\title{
An investigation on the modelling of kinetics of thermal decomposition of hazardous mercury wastes
}

\author{
Yailen Busto $^{\mathrm{a}, \mathrm{b}, *}$, Filip M. G. Tack ${ }^{\mathrm{b}}$, Luis M. Peralta ${ }^{\mathrm{a}}$, Xiomara Cabrera ${ }^{\mathrm{a}}$, \\ Luis E. Arteaga-Pérez ${ }^{a, c}$ \\ a Departamento de Ingeniería Química, Facultad de Química y Farmacia, Universidad Central “Marta Abreu” de las Villas, C. Camajuaní km. 5 1/2, Santa \\ Clara, Cuba \\ ${ }^{\mathrm{b}}$ Laboratory for Analytical Chemistry and Applied Ecochemistry, Bioengineering Science Faculty, Ghent University, Coupure Links 653, B-9000 Ghent, \\ Belgium

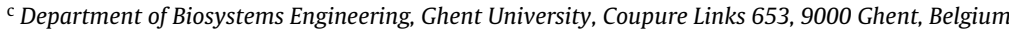

\section{H I G H L I G H T S}

- A reaction mechanism of thermal treatment of hazardous mercury waste is postulated.

- The kinetic model for the thermal decomposition of mercury solid waste is deduced.

- A methodology to investigate reaction order models in solid systems is proposed.

- The thermal decomposition of mercury waste is described by two modelling approaches.

\section{A R T I C L E I N F O}

\section{Article history:}

Received 16 January 2013

Received in revised form 20 May 2013

Accepted 23 May 2013

Available online 30 May 2013

\section{Keywords:}

Mercury kinetic model

Hazardous mercury waste

Isoconversional method

Thermal decomposition mechanism

Chlor-alkali plant

\begin{abstract}
A B S T R A C T
The kinetics of mercury removal from solid wastes generated by chlor-alkali plants were studied. The reaction order and model-free method with an isoconversional approach were used to estimate the kinetic parameters and reaction mechanism that apply to the thermal decomposition of hazardous mercury wastes. As a first approach to the understanding of thermal decomposition for this type of systems (poly-disperse and multi-component), a novel scheme of six reactions was proposed to represent the behaviour of mercury compounds in the solid matrix during the treatment. An integration-optimization algorithm was used in the screening of nine mechanistic models to develop kinetic expressions that best describe the process. The kinetic parameters were calculated by fitting each of these models to the experimental data. It was demonstrated that the $D_{1}$-diffusion mechanism appeared to govern the process at $250^{\circ} \mathrm{C}$ and high residence times, whereas at $450^{\circ} \mathrm{C}$ a combination of the diffusion mechanism $\left(D_{1}\right)$ and the third order reaction mechanism $\left(F_{3}\right)$ fitted the kinetics of the conversions. The developed models can be applied in engineering calculations to dimension the installations and determine the optimal conditions to treat a mercury containing sludge.
\end{abstract}

() 2013 Elsevier B.V. All rights reserved.

\section{Introduction}

Mercury represents a huge environmental threat because it is highly toxic and persistent. It bio-accumulates and can cause neurological damage [1]. Anthropogenic emissions of mercury are causing a general increase in mercury pollution at local, regional and global scales [2]. The three largest secondary sources of mercury anthropogenic emissions include artisanal and small-scale

\footnotetext{
* Corresponding author at: Departamento de Ingeniería Química, Facultad de Química y Farmacia, Universidad Central "Marta Abreu" de las Villas, C. Camajuaní km. 51/2, Santa Clara, Cuba. Tel.: +53 42281738.

E-mail address: yailen.bustoyera@ugent.be (Y. Busto).
}

gold mining, the production of vinyl chloride where mercuric chloride is used as catalyst, and the chlor-alkali industry [3,4].

The amount of mercury in wastes produced by chlor-alkali plants in 1995 was estimated (EU-15+Switzerland) to amount at about 95.2 tonne based on $14-17 \mathrm{~g} \mathrm{Hg} /$ tonne $\mathrm{Cl}_{2}$ capacity, only in the EU [5]. In 2000, the chlor-alkali industry was responsible for about $17 \%$ of the total anthropogenic mercury emissions in Europe with a total impact of 40.4 tonne/y [6].

Over the last decades, increased awareness of the negative impact of mercury for the environment and human health has led to stronger regulations for its emissions. Mercury cell chlor-alkali plants are not any more considered good industrial practice. The Integrated Pollution Prevention and Control (IPPC) of the European Union has indicated that chlor-alkali installations are required to obtain licenses based on the Best Available Techniques. 
Table 1

Extractants and mercury fractions defined in the sequential extraction procedure.

\begin{tabular}{|c|c|c|c|}
\hline Fraction ID & Extractant & Extractant $(\mathrm{ml})$ :waste $(\mathrm{g})$ ratio & Hg fraction \\
\hline F1 & Deionized water & $20: 2$ & Water soluble \\
\hline $\mathrm{F} 2$ & $0.5 \mathrm{~mol} / 1 \mathrm{NH}_{4}-\mathrm{EDTA}(\mathrm{pH} 8.4)$ & $20: 2$ & Exchangeable \\
\hline F3 & $0.2 \mathrm{M} \mathrm{NaOH}$ and $4 \% \mathrm{CH}_{3} \mathrm{COOH}$ & $20: 2$ & Organic \\
\hline F4 & $10 \mathrm{ml} \mathrm{HNO}_{3 \text { conct }}$ and $15 \mathrm{ml} \mathrm{H}_{2} \mathrm{SO}_{4 \text { conct }}$ & $25: 0.5$ & Residual \\
\hline
\end{tabular}

In the United States, only five mercury plants were kept in operation by late 2008. In Europe in 2006, mercury cells accounted for $43 \%$ of the mounted capacity. Western European producers have been committed to closing or converting all remaining chloralkali mercury plants by 2020 [7]. Although the technology is being phased out, the potential risk represented by thousands of tonnes of mercury wastes generated by this process will remain for a long period of time.

Cuba as a developing country still uses mercury cell technology to produce gaseous chlorine and caustic soda. It currently hosts more than 7000 tonnes of mercury contaminated wastes buried in concrete niches. Mercury wastes generated by the electrochemical Cuban plant were characterized as 'high mercury waste' (total $\mathrm{Hg}$ content exceeding $260 \mathrm{mg} / \mathrm{kg}$ ) according to the US Land Disposal Restrictions [8]. According to USEPA [9], thermal treatment represents the most suitable technology for 'high mercury wastes'. The potential of this approach to decontaminate the mercury containing wastes from the chlor-alkali industry in Cuba has been investigated in a previous contribution [10].

Despite the fact that thermal treatment, in particular by retorting, is a widely used technology to treat solid wastes with high content of mercury (e.g. mercury wastes from the chlor-alkali process), almost all studies have focused on optimizing operating conditions at pilot and industrial scale [11-15]. Very few studies have been published on reaction mechanisms that may represent mercury behaviour during the thermal treatment [16]. On the other hand, several kinetic models exist for homogeneous mercury reactions in the gas phase. Most of these studies have been dedicated to unravel the reaction mechanisms of mercury oxidation, specifically in the context of exhaust gases emitted from coal-fired power plants [17-27]. An elementary reaction mechanism for homogeneous $\mathrm{Hg}^{0}$ oxidation with an emphasis on major interactions among $\mathrm{Cl}$-species and other pollutants in coal derived exhausts has been proposed and evaluated [21]. The kinetic mechanism of mercury oxidation, by ab initio calculations of quantum chemistry, has been studied and the rate constant calculated using the transition state theory [24]. Recently, the rate constants for the 8-step homogeneous $\mathrm{Hg}-\mathrm{Cl}$ reaction mechanism that describes mercury oxidation in combustion systems have been determined using the transition state theory [26].

Heterogeneous mercury reactions have been less studied. Only thermal decomposition of mercury oxide seems to play an important role in the knowledge of the mercury solid phase reactions [27]. The kinetic and thermal decomposition of $\mathrm{HgO}$ was studied and a dissociative evaporation scheme that includes two different $\mathrm{HgO}(\mathrm{s})$ reactions at high $(<650 \mathrm{~K})$ and low decomposition temperature was developed [27]. Moreover, an investigation of the retardation effect of oxygen on the evaporation rate of $\mathrm{HgO}$ concluded that the dissociative evaporation of $\mathrm{HgO}$ proceeds with the release of atomic oxygen as a primary product of decomposition [28]. Nevertheless, based on a literature survey, there are no kinetic and thermodynamic studies about the mechanism of mercury removal from solid wastes generated in chlor-alkali industries during thermal decomposition which includes homogeneous and heterogeneous reactions for mercury contaminated wastes generated by chloralkali industries.
This paper intends to elucidate the kinetics of the mercury removal from solid wastes by thermal decomposition using two different approaches, a model-free based on a differential isoconversional approach and reaction order methods. Moreover, as a first depth into the knowledge of thermal decomposition for this type of systems (poly-disperse and multi-component), this communication aims to obtain the reaction pattern and the thermodynamic feasibility of the studied system considering both homogeneous and heterogeneous reactions.

\section{Experimental}

\subsection{Sampling and chemical analysis}

The mercurial sludge sample used for the experiments was collected from a filled niche, located around the Cuban chlor-alkali production facility "ELQUIM". The procedures applied to sampling, sample preparation and chemical analysis have been described in a previous paper [10].

\subsection{Mercury fractionation}

Fractionation by using a sequential extraction constitutes an operationally defined procedure that allows to identify various classes of species of an element and to determine the sum of its concentrations in each class [30].

The fractionation of $\mathrm{Hg}$ was performed according to the four step procedure outlined by Neculita et al. [31] (Table 1).

The extraction was performed using $2 \mathrm{~g}$ of accurately weighted sample mixed with $20 \mathrm{ml}$ of solvent in a $100 \mathrm{ml}$ centrifuge tube. The tubes were thoroughly shaken for $2 \mathrm{~h}$ at $20 \pm 2{ }^{\circ} \mathrm{C}$ using an end over end shaker operating at about $30 \mathrm{rpm}$. Between each extraction and rinse step, the supernatant was obtained by centrifuging at $3000 \mathrm{rpm}$ for $15 \mathrm{~min}$ at $10^{\circ} \mathrm{C}$ followed by filtration using $0.45 \mu \mathrm{m}$ pore membrane filters. The rinsing steps consisted of washing the leached residues twice with deionised water $(20$ and $10 \mathrm{ml})$ during $15 \mathrm{~min}$. Rinses were always subsequently added to the solvent extract from the same sample. The resulting combined supernatant from the first three extraction steps was analyzed for total $\mathrm{Hg}$ content by CVAAS. Residual $\mathrm{Hg}$ was extracted by adding the same reagents as for total $\mathrm{Hg}$ determination in the waste sample directly in the original $100 \mathrm{ml}$ centrifuge tube. The sample was then transferred into a $100 \mathrm{ml}$ standard volumetric flask. The digestion was performed using the same procedure as previously described for total $\mathrm{Hg}$ in the waste sample [10].

\subsection{Thermal treatment}

The thermal decomposition technology of these mercury wastes, which is based on volatilization and subsequent condensation of the mercury vapours, results in the recovery of metallic mercury [13,32].

The thermal treatment of the mercurial sludge was performed at laboratory scale using a ceramic muffle furnace (L9/11/SKM/P330 Model, Nabertherm, Germany, Bremen) which has a temperature control accuracy of $\pm 1{ }^{\circ} \mathrm{C}$. The oven was placed inside a fume 
cupboard (Model Potteau, Belgium) to avoid pollution with mercury vapours.

The thermal decomposition of the sample was studied in a flowing atmospheric air stream and at isothermal conditions. A quantification of the total mercury removal was conducted at different temperatures, 250,350 and $450^{\circ} \mathrm{C}$, and reaction times, 5,10 , $15,20,25,30,40,50,60,90,120$ and $150 \mathrm{~min}$.

The tests were carried out by ashing $3 \mathrm{~g}$ of dried and grounded mercury waste in a porcelain crucible. A dried ( $1 \%$ of humidity) and grounded ( $2 \mathrm{~mm}$ sieve) mercury waste sample was used in all thermal experiments to decrease the diffusional resistances improving the mass and heat transfer and subsequently the mercury removal efficiency. Industrial chlor-alkali facilities typically generate a hazardous mercury waste with a relatively high content of water [33]. For instance, in Cuba, the mercurial sludge has approximately a water content of $50 \%$ (information provided by workers of the Cuban plant). Several studies report that humidity of this type of waste at values below $5 \%$ avoids operational interferences during the thermal process $[34,35]$. Moreover, as the thermal decomposition reactions in the solid phase are considered a fast processes influenced by the temperature but limited by the diffusion and particle size of the mercury waste sample [36,37], a pre-treatment system which includes drying and crushing stages of the mercury waste is recommended.

The mercury removal was estimated by the differences between the total mercury content in the original sample and in the ashes obtained after each experiment. The samples resulting from retorting temperatures of 250,350 and $450^{\circ} \mathrm{C}$ and times of $5,25,60,120$ and $150 \mathrm{~min}$, were subjected to a TCLP test in order to evaluate the influence of the retorting temperature on the toxicity classification of the treated sample. The USEPA toxicity characteristics leaching procedure (TCLP) [29] is a standardized testing methodology used to determine if a waste is characteristically hazardous. It involves an extraction of $1 \mathrm{~g}$ of sample with $20 \mathrm{ml}$ of either acetic acid/acetate buffer or acetic acid, depending on the alkalinity of the test material. Our samples required the use of acetic acid. Details of the procedure can be found in a previous contribution [10].

\subsection{Thermodynamic analysis}

Thermodynamic analysis was performed using a well-known methodology reported by Smith [38], which is based on Kirchhoff's equation. This equation expresses the temperature dependence of the thermal quantities associated with a chemical reaction. To obtain the thermodynamic parameters for reaction $j$ through Mondeja's Methodology [39], the following equations were considered:

$$
\begin{aligned}
& \Delta C p=\Delta \alpha_{i} \cdot T+\Delta \beta_{i} \cdot T^{2}+\Delta \gamma_{i} \cdot T^{3} \\
& \Delta H_{j}=I H_{j}+\Delta \alpha_{i} \cdot T+\frac{\Delta \beta_{i}}{2} \cdot T^{2}+\frac{\Delta \gamma_{i}}{3} \cdot T^{3} \\
& I H_{j}=\Delta H^{0}-\Delta \alpha_{i} \cdot \operatorname{Tr}-\frac{\Delta \beta_{i}}{2} \cdot \operatorname{Tr}^{2}-\frac{\Delta \gamma_{i}}{3} \cdot \operatorname{Tr}^{3} \\
& \Delta G_{j}=I H_{j}-\Delta \alpha_{i} \cdot T \cdot \ln (T)-\frac{\Delta \beta_{i}}{2} \cdot T^{2}-\frac{\Delta \gamma_{i}}{6} \cdot T^{3}-I K_{j} \cdot R \cdot T \\
& I K_{j}=\frac{\left(I H_{j}-\Delta \alpha_{i} \cdot \operatorname{Tr} \cdot \ln (\operatorname{Tr})-\left(\Delta \beta_{i} / 2\right) \cdot \operatorname{Tr}^{2}-\left(\Delta \gamma_{i} / 6\right) \cdot \operatorname{Tr}^{3}-\Delta G^{0}\right.}{R \cdot T r}
\end{aligned}
$$

$\ln K e_{j}=\frac{-I H_{j}}{R \cdot T}+\frac{\Delta \alpha_{i} \cdot \ln (T)}{R}+\frac{\Delta \beta_{i} \cdot T}{2 R}+\frac{\Delta \gamma_{i} \cdot T^{2}}{6 R}+I K_{j}$
Table 2

Reaction scheme of the mercury solid wastes thermal decomposition.

\begin{tabular}{lrl}
\hline Reaction & & Reference \\
\hline $\mathrm{HgS}_{(\mathrm{c})}+\frac{3}{2} \mathrm{O}_{2(\mathrm{~g})} \rightarrow \mathrm{HgO}_{(\mathrm{g})}+\mathrm{SO}_{2(\mathrm{~g})}$ & $\left(\mathrm{R}_{1}\right)$ & {$[40]$} \\
$\mathrm{HgO}_{(\mathrm{g})} \rightarrow \mathrm{Hg}_{(\mathrm{g})}+\frac{1}{2} \mathrm{O}_{2(\mathrm{~g})}$ & $\left(\mathrm{R}_{2}\right)$ & {$[41]$} \\
$\mathrm{HgS}_{(\mathrm{c})}+\mathrm{CaO}_{(\mathrm{c})} \rightarrow \mathrm{Hg}_{(\mathrm{g})}+\frac{3}{4} \mathrm{CaS}_{(\mathrm{c})}+\frac{1}{4} \mathrm{CaSO}_{4(\mathrm{c})}\left(\mathrm{R}_{3}\right)$ & {$[40]$} \\
$\mathrm{HgSO}_{4(\mathrm{c})} \rightarrow \mathrm{Hg}_{(\mathrm{g})}+\mathrm{SO}_{2(\mathrm{~g})}+\mathrm{O}_{2(\mathrm{~g})}$ & $\left(\mathrm{R}_{4}\right)$ & {$[40]$} \\
$\mathrm{HgS}_{(\mathrm{c})}+\mathrm{Fe}_{(\mathrm{c})} \rightarrow \mathrm{Hg}_{(\mathrm{g})}+\mathrm{FeS}_{(\mathrm{c})}$ & $\left(\mathrm{R}_{5}\right)$ & {$[40]$} \\
$\mathrm{HgCl}_{2(\mathrm{aq})} \rightarrow \mathrm{Hg}_{(\mathrm{g})}+\mathrm{Cl}_{2(\mathrm{~g})}$ & $\left(\mathrm{R}_{6}\right)$ & {$[40]$} \\
\hline
\end{tabular}

where $\alpha_{i}, \beta_{i}$ and $\gamma_{i}$ are the coefficients of the empiric model with polynomial adjust, which correlate the heat capacity $(C p)$ with the temperature $(T) ; T_{r}$ is the reference temperature $(298 \mathrm{~K}) . I K_{j}$ and $I H_{j}$ are integration constants for the heat of formation $\left(\Delta H_{j}\right)$ and the Gibbs free energy $\left(\Delta G_{j}\right)$ of the reaction considered, and $K e_{j}$ represents its equilibrium constant. Solving this set of equations for $\alpha_{i}, \beta_{i}$ and $\gamma_{i}$ yields models that account for changes in the heat capacity with temperature $(\Delta C p)$, and allow to estimate $\Delta H_{j}, \Delta G_{j}$ and $K e_{j}$ as a function of temperature.

A scheme that involves six homogeneous and heterogeneous reactions was proposed (Table 2 ).

The chemical and physical composition of the sludge and the mercury fractionation [42] with the presence of $\mathrm{HgCl}_{2}, \mathrm{HgS}$ and $\mathrm{HgSO}_{4}$ in the sludge matrix were taken into account. Thermodynamic data to determine the $\Delta H^{\circ}$ and $\Delta G^{\circ}$ at reference temperature (298 K) were obtained from Green and Perry [43] for several species $\left(\mathrm{HgCl}_{2}, \mathrm{SO}_{2}, \mathrm{HgO}, \mathrm{CaO}, \mathrm{CaSO}_{4}, \mathrm{Cl}_{2}, \mathrm{Fe}\right.$ and $\left.\mathrm{FeS}\right)$. For the species with no specific data the parameters were estimated correlating experimental $C p$ values at different temperatures [44].

\subsection{Kinetics of thermal decomposition of the mercury solid waste}

Two methods widely discussed in the literature were applied to describe the kinetic behaviour of mercurial sludge thermal decomposition. First, the apparent activation energy was calculated using the model-free method of Friedman, based on the differential isoconversional approach. Second, the reaction order model was applied to find the reaction mechanism that best describes the treatment process; this second method was solved for a scheme involving six reactions instead of using one global equation.

\subsubsection{Model-free method}

The kinetic study of the thermal decomposition using the method of Friedman assumes that the reaction rate is only a function of temperature and the conversion function remains invariable; as such, the activation energy $(E)$ can be calculated a priori.

The kinetic equation can be expressed in general terms as:

$\frac{d \alpha}{d t}=\beta\left(\frac{d \alpha}{d T}\right)=A \cdot \exp \left(-\frac{E}{R T}\right) \cdot f(\alpha)$.

Taking natural logarithms at both sides of the equation yields

$\ln \left(\frac{d \alpha}{d t}\right)=\ln \left[\beta\left(\frac{d \alpha}{d T}\right)\right]=\ln (A f(\alpha))-\frac{E}{R T}$.

Here $t$ represents the time ( $\mathrm{min}) . R$ and $T$ are the universal gas constant $\left(8.3144 \times 10^{-3} \mathrm{~kJ} \mathrm{~mol}^{-1} \mathrm{~K}^{-1}\right)$ and the reaction temperature, respectively $\left({ }^{\circ} \mathrm{C}\right) . \beta$ is the heating rate (for non-isothermal experiments), whereas the parameter $\alpha$ represents the conversion of the mercury containing species, expressed as the fraction between the number of moles consumed during reaction and the mercury content of mercury in the sample expressed in moles:

$\alpha=\frac{n_{0}-n}{n_{0}}$ 
Table 3

Empirical kinetic model $(\alpha)$ functions for solid state thermal decomposition reactions.

\begin{tabular}{|c|c|c|}
\hline & Symbol & $F(\alpha)$ \\
\hline \multicolumn{3}{|l|}{ (1) Sigmoid $\alpha$-T curves } \\
\hline (a) Prout-Tompkins equation & $B_{1}$ & $\alpha(1-\alpha)$ \\
\hline \multicolumn{3}{|l|}{ (1.1) Nucleation and nuclei growth } \\
\hline (a) Random nucleation-Avrami-Erofeev equation I & $A_{2}$ & $2(1-\alpha)[-\ln (1-\alpha)]^{1 / 2}$ \\
\hline (b) Random nucleation-Avrami-Erofeev equation II & $A_{3}$ & $3(1-\alpha)[-\ln (1-\alpha)]^{2 / 3}$ \\
\hline (c) Random nucleation-Avrami-Erofeev equation III & $A_{4}$ & $4(1-\alpha)[-\ln (1-\alpha)]^{3 / 4}$ \\
\hline \multicolumn{3}{|l|}{ (2) Acceleratory $\alpha-T$ curves } \\
\hline (a) Exponential law & $E_{1}$ & $\alpha$ \\
\hline \multicolumn{3}{|l|}{ (3) Deceleratory $\alpha$-T curves } \\
\hline \multicolumn{3}{|l|}{ (3.1) Reaction order } \\
\hline (a) First order - unimolecular decay law & $F_{1}$ & $(1-\alpha)$ \\
\hline (b) Second order & $F_{2}$ & $(1-\alpha)^{2}$ \\
\hline (a) Third order & $F_{3}$ & $0.5(1-\alpha)^{3}$ \\
\hline \multicolumn{3}{|l|}{ (3.2) Diffusion mechanisms } \\
\hline (a) Parabolic law, one-dimensional diffusion & $D_{1}$ & $0.5 \alpha^{-1}$ \\
\hline (b) Valesi, two-dimensional diffusion & $D_{2}$ & {$[-\ln (1-\alpha)]^{-1}$} \\
\hline (c) Jander, three-dimensional diffusion, spherical symmetry & $D_{3}$ & $(3 / 2)(1-\alpha)^{2 / 3}\left[1-(1-\alpha)^{1 / 3}\right]^{-1}$ \\
\hline (d) Ginstling-Brounshtein, three-dimensional diffusion, spherical symmetry & $D_{4}$ & $(3 / 2)\left[(1-\alpha)^{-1 / 3}-1\right]^{-1}$ \\
\hline \multicolumn{3}{|l|}{ (3.3) Phase-boundary reaction } \\
\hline (a) Two-dimensional (cylindrical geometry) & $R_{2}$ & $2(1-\alpha)^{1 / 2}$ \\
\hline (b) Three-dimensional (spherical geometry) & $R_{3}$ & $3(1-\alpha)^{2 / 3}$ \\
\hline
\end{tabular}

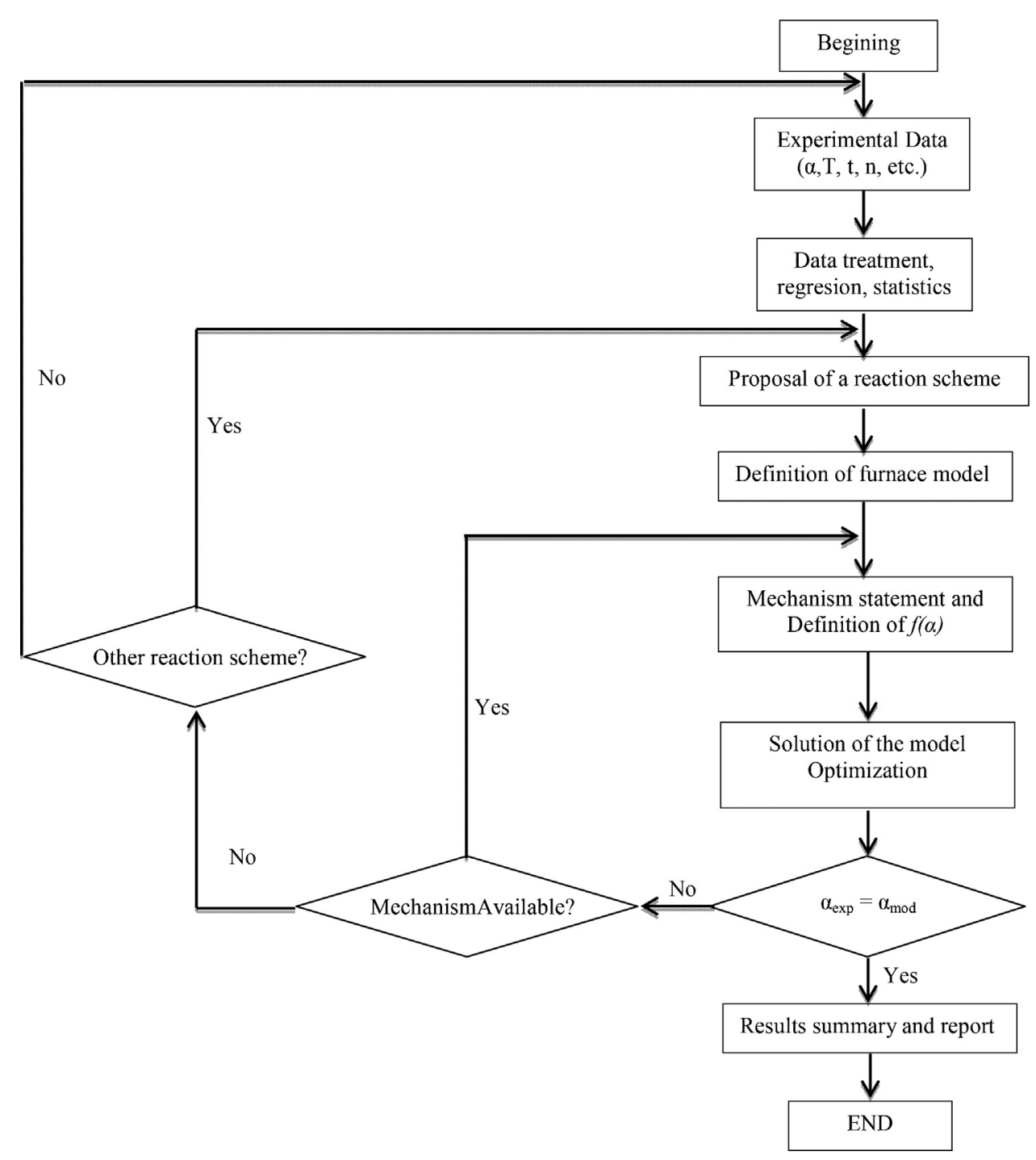

Fig. 1. Algorithm used to investigate the reaction mechanism and to define the kinetic model. 
Table 4

Initial data and design parameters used in the mercury solid wastes thermal decomposition at bench scale.

\begin{tabular}{|c|c|c|c|}
\hline Nomenclature & Symbols & Values & Units \\
\hline \multicolumn{4}{|l|}{ Initial data from chemical-physical analyses } \\
\hline Sludge mass inlet to the laboratory furnace & $m T_{0}$ & 3 & $\mathrm{~g}$ \\
\hline Sludge humidity & $h T_{0}$ & 0.032 & $\mathrm{~g}$ \\
\hline Mass fraction of $\mathrm{HgS}$ & $x M s_{0}$ & 0.429 & $\mathrm{~kg} \mathrm{HgS/} / \mathrm{kg}$ total Hg \\
\hline Mass fraction of $\mathrm{HgCl}_{2}$ & $x \mathrm{Mcm}_{0}$ & 0.502 & $\mathrm{~kg} \mathrm{HgCl} / 2 / \mathrm{kg}$ total $\mathrm{Hg}$ \\
\hline Mass fraction of metallic $\mathrm{Hg}$ & $x M m_{0}$ & 0.031 & $\mathrm{~kg} \mathrm{Hg}^{0} / \mathrm{kg}$ total $\mathrm{Hg}$ \\
\hline Mass fraction of $\mathrm{HgSO}_{4}$ & $x M s u_{0}$ & 0.022 & $\mathrm{~kg} \mathrm{HgSO}_{4} / \mathrm{kg}$ total $\mathrm{Hg}$ \\
\hline Total initial Hg content in the sludge/g of sludge & $x M T_{0}$ & $1.32-10^{-3}$ & $\mathrm{~kg}$ total $\mathrm{Hg} / \mathrm{kg}$ sludge \\
\hline Organic matter content/g of sludge & $x \mathrm{MO}_{0}$ & 0.144 & kg Org. Mat./kg sludge \\
\hline Carbonate content/g of sludge & $x C a_{0}$ & 0.633 & $\mathrm{~kg}$ Carbonate/kg sludge \\
\hline \multicolumn{4}{|l|}{ Design parameters of the simulated Muffle furnace } \\
\hline Length of the furnace & $L$ & 0.24 & $\mathrm{~m}$ \\
\hline Width of the furnace & $W$ & 0.24 & $\mathrm{~m}$ \\
\hline Height of the furnace & $H$ & 0.17 & $\mathrm{~m}$ \\
\hline Number of electric resistance strip & Nut & 75 & - \\
\hline Length of the strip & $\mathrm{Lt}$ & 0.79 & $\mathrm{~m}$ \\
\hline Length of the hot strip & Lct & 0.69 & $\mathrm{~m}$ \\
\hline Power of the simulated furnace & Kwe & 0.09 & $\mathrm{~kW} / \mathrm{cm}$ of steel \\
\hline Air humidity & Hair & 65 & $\%$ \\
\hline Reaction time & $T$ & 150 & $\min$ \\
\hline
\end{tabular}

where $n_{0}$ and $n$ represent the initial and final moles for each reaction.

In Eq. (8), $f(\alpha)$ represents an empirical kinetic model function of $\alpha$ which is assumed to remains constant, i.e., the mercury conversion is only dependent on the rate of mass loss. Thus, a plot of $\ln [d \alpha / d t]$ versus $1 / T$ yields a straight line with intercept equal to the log of the Arrhenius apparent activation energy, and slope equal to $-E / R$.

This model-free approach does not require previous knowledge about the reaction mechanism and avoids systematic errors that may result when estimating Arrhenius parameters from a kinetic analysis.

One of the objectives of the present paper is to elucidate a reaction mechanism and the correspondent kinetic model. This first calculation allows identifying the possible divergences in the values of activation energy derived from a reaction order method. Once the activation energy $E$ has been determined, a reaction order model can be used to find the kinetic model that fits the measured data.

\subsubsection{Reaction order model}

The reaction order models can be fitted to experimental data obtained at both isothermal and non-isothermal conditions. The kinetic expressions for isothermal reaction can be represented by a canonical equation as follows:

$\frac{d \alpha}{d t}=k(T) f(\alpha)=A \cdot \exp \left(\frac{-E}{R T}\right) \cdot f(\alpha)$,

for which $f(\alpha)$ may, depending on the controlling mechanism, take different forms as presented in Table 3. The so-called triplet $A, E$ and $f(\alpha)$ is the group of parameters often used to characterize the kinetics.

A six reaction scheme involving a wide range of mercury compounds such as $\mathrm{Hg}, \mathrm{HgCl}_{2}, \mathrm{HgO}, \mathrm{HgSO}_{4}$ and $\mathrm{HgS}$ was considered to derive the mass balance and kinetic differential equations, and to estimate the triplet of the thermal decomposition. The consistency of the new $E$ values with respect to those obtained from the isoconversional approach was checked.

\subsubsection{Mathematical simulation procedure}

The mass balance equations and kinetic models of the mercury sludge thermal decomposition were simulated in an integrationoptimization algorithm. Fig. 1 represents the algorithm used to determine the triplet and to elucidate the reaction mechanism. The proposed algorithm constitutes a novel heuristic scheme for kinetic modelling which involves the solution of differential algebraic equations (DAE) and the optimization of the kinetic parameters using the Hooke and Jeeves method with variable step. The Hooke and Jeeves method is a 'pattern search procedure' widely used to optimize non-linear functions that are not necessarily continuous or differentiable and to determine the optimal value of a variable considering its perturbations $[45,46]$.

The thermal treatment was carried out at batch operating conditions and assuming perfect mixing in the oven. Initial data and the main design operational parameters of the furnace are listed in Table 4.

2.5.3.1. Furnace model description. The general expressions of the material balance were established as follows:

- Total material balance in the solid matrix (mercurial sludge):

$$
\frac{d M}{d t}=V \cdot \sum n_{i j} \cdot R_{j} \cdot M W_{i}
$$

- Material balance by component:

$$
\frac{d n_{i}}{d t}=V \cdot \sum( \pm) n_{i j} \cdot R_{j}-F_{i}
$$

where $M, V, n$ and $R_{j}$ are the sludge mass $(\mathrm{g})$, furnace volume $\left(\mathrm{m}^{3}\right)$, moles of specie $(i)$ in the reaction $(j)$ and the reaction rate, respectively, $M W$ is the molecular weight $(\mathrm{g} / \mathrm{mol})$ and $F_{i}$ is the outlet molar flow ( $\mathrm{mol} / \mathrm{min})$ of reaction species $i$.

Species $i=\mathrm{O}_{2(\mathrm{~g})}, \mathrm{SO}_{2(\mathrm{~g})}, \mathrm{H}_{2} \mathrm{O}_{(\mathrm{g})}, \mathrm{Hg}_{(\mathrm{g})}, \mathrm{N}_{2(\mathrm{~g})}, \mathrm{H}_{2} \mathrm{O}_{(\mathrm{aq})}, \mathrm{HgCl}_{2(\mathrm{aq})}, \mathrm{Hg}_{(\mathrm{aq})}, \mathrm{HgS}_{(\mathrm{c})}, \mathrm{HgSO}_{4(\mathrm{c})}$. Reaction $j=1$ to 11 (see below)

The reaction rate was determined by substituting $f(\alpha)$ in Eq (10) by expressions for the different solid state mechanisms as presented in Table 3. The kinetic rates for gas phase reactions $\left(R_{1}\right.$ and $R_{4}$ ) were represented as:

$R_{1}=k_{1} \cdot \mathrm{pHgS} \cdot \mathrm{pO}_{2}{ }^{3 / 2}$

$R_{4}=k_{4} \cdot \mathrm{pHgSO}_{4}$

where $\mathrm{pHgS}$ and $\mathrm{pO}_{2}$ are the partial pressure of $\mathrm{HgS}$ and $\mathrm{O}_{2}(\mathrm{~Pa})$.

2.5.3.2. Solution of the integration-optimization algorithm. The fourth order Runghe Kutta method [47] was used to solve the mass balance equations. The kinetic parameters $\left(k_{j}, n_{r}\right)$ at each temperature were calculated by the nonlinear optimization method of Hooke and Jeeves [45]. 
Table 5

Properties and metal contents of mercurial sludge sample (means \pm standard deviations, $n=3$ ).

\begin{tabular}{lc}
\hline Parameters & $\begin{array}{c}\text { Mercurial } \\
\text { sludge sample }\end{array}$ \\
\hline $\mathrm{pH}-\mathrm{H}_{2} \mathrm{O}$ & $9.5(0.1)$ \\
Carbonate content $(\mathrm{g} / \mathrm{kg} \mathrm{DM})$ & $633(6)$ \\
Org Matter content $(\mathrm{g} / \mathrm{kg} \mathrm{DM})$ & $144(4)$ \\
$\mathrm{EC}(\mathrm{mS} / \mathrm{cm})$ & $34(0.1)$ \\
Total metal content $(\mathbf{g} / \mathbf{k g ~ D M})$ & \\
$\mathrm{Ca}$ & $191(2)$ \\
$\mathrm{Mg}$ & $36(1)$ \\
$\mathrm{Na}$ & $50(1)$ \\
$\mathrm{Fe}$ & $13(0.1)$ \\
$\mathrm{Al}$ & $9(0.1)$ \\
$\mathrm{Hg}$ & $1.3(0.1)$ \\
$\mathrm{Total}$ metal content $(\mathbf{m g} / \mathbf{k g ~ D M})$ & \\
$\mathrm{Cd}$ & $2(0.1)$ \\
$\mathrm{Cr}$ & $24(0.1)$ \\
$\mathrm{K}$ & $942(18)$ \\
$\mathrm{Mn}$ & $239(1)$ \\
$\mathrm{Ni}$ & $20(1)$ \\
$\mathrm{Pb}$ & $58(1)$ \\
$\mathrm{Zn}$ & $136(1)$ \\
$\mathrm{Cu}$ & $243(13)$ \\
$\mathrm{Metal}$ concentration in the TCLP leachate (mg/l) & \\
$\mathrm{Hg}$ & $2.5(0.3)$ \\
\hline
\end{tabular}

The objective function (Eq. (15)) was defined to minimize the differences between experimentally observed conversion and model calculated values at the same conditions:

$F_{\mathrm{obj}}=\min \sum_{t}\left(\alpha_{\mathrm{fmod}}-\alpha_{f_{\mathrm{exp}}}\right)^{2}$

where $\alpha_{\text {fmod }}$ and $\alpha_{f_{\text {exp }}}$ are the conversions obtained from the model and from the experimental data.

A statistical analysis using the non-parametric tests of Ranksum and Kruskal-Wallis $[48,49]$ was applied to evaluate the model accuracy and to establish the mechanism that best fitted the observations.

\section{Results and discussion}

\subsection{Characteristics of mercurial sludge}

Properties of the mercurial sludge used in current experiment are summarized in Table 5. The mercurial waste exhibited an alkaline $\mathrm{pH}$ of $9.5 \pm 0.01$. Carbonate content was in the order of the $60 \mathrm{w} \%$, whereas pseudo total analysis revealed high Ca and Mg levels (Table 5). The high organic matter (OM) content found in the sample could be attributed to the presence of other materials that are eventually disposed in the niches such as activated carbon from filters used in the electrolytic process.

The high value of electrical conductivity (EC) indicates a significant presence of soluble salts. Moreover, high levels of $\mathrm{Ca}, \mathrm{Mg}$, and $\mathrm{Na}$ in the mercurial waste were associated with the use of various compounds to stabilize the sludge. These include $\mathrm{Na}_{2} \mathrm{CO}_{3}$ and $\mathrm{NaOH}$ for purification of the brine, $\mathrm{Na}_{2} \mathrm{~S}$ for precipitation of $\mathrm{Hg}$, and calcareous products such as $\mathrm{CaCO}_{3}$ and $\mathrm{Mg}(\mathrm{OH})_{2}$ which are used to increasing the $\mathrm{pH}$. As expected, the mercurial waste contains significant amounts of $\mathrm{Hg}$ at about $1300 \pm 100 \mathrm{mg} / \mathrm{kg}$, allowing the material to be classified as hazardous high mercury wastes according to US EPA: land disposal restrictions [33]. A detailed analysis of the chemical characteristics of this mercurial sludge can be found in a previous contribution [10].

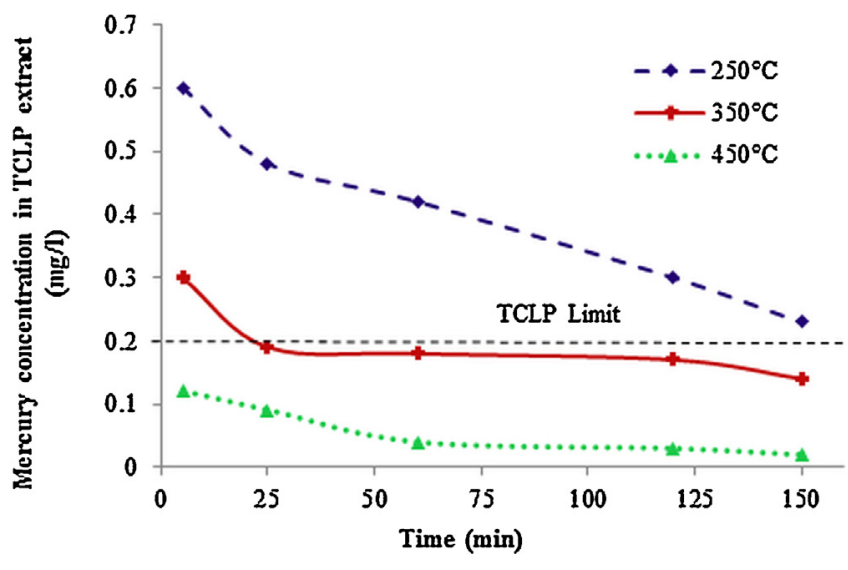

Fig. 2. Mercury concentrations (TCLP test) in ashes with the retorting time at three different temperatures.

\subsection{Fractionation of mercurial sludge}

The sum of the sequentially extracted fractions amounted to $95 \pm 2 \%$ of the total $\mathrm{Hg}$ content, indicating a good recovery. The residual fraction, $F_{4}$, represented the largest fraction, including $43 \pm 1 \%$ of the total content. The residual fraction has been linked to the presence of $\mathrm{HgS}$. The precipitation reaction with $\mathrm{Na}_{2} \mathrm{~S}$ promotes the formation of $\mathrm{HgS}$. The second main group of mercury species was extracted within the "exchangeable phase" $\left(F_{2}\right)$, which represented $39 \pm 1 \%$ of the total content. This fraction can be related to soluble species of mercury in the oxic layer of the waste matrix. The water-soluble fraction $\left(F_{1}\right)$ represented $13.8 \pm 0.8 \%$ of total mercury content. The more mobile $\mathrm{Hg}$ fractions $\left(F_{1}+F_{2}\right)$ represent the major fraction of the total mercury found in the sample (52.3\%), indicating a high risk of $\mathrm{Hg}$ mobilization by the presence of water soluble and exchangeable mercury compounds such as $\mathrm{HgCl}_{2}, \mathrm{HgSO}_{4}$ and $\mathrm{Hg}$. The fractionation method provides approximate information about the possible mercury species present in this mercurial waste [42].

\subsection{Thermal treatment of the mercurial sludge sample}

Mercury contents remaining in the solid ashes were evaluated as a function of treatment time for three temperatures (250, 350 and $450^{\circ} \mathrm{C}$ ). Removal rates were 43,95 and $97 \%$ for 250,350 and $450^{\circ} \mathrm{C}$, respectively. Release of $\mathrm{Hg}$ from the matrix was markedly slower at the lowest temperature tested, $250^{\circ} \mathrm{C}$, where maximum removal was achieved after about $30 \mathrm{~min}$. At higher treatment temperatures, release was almost instantaneous. Most of the mercury was already removed after 5 min of treatment. This can be explained by a change in the controlling reaction mechanism between the different treatment temperatures and to differences in heat and mass transfer resistance in the solid particle. Although, allowing sufficient time, more than $90 \%$ of the mercury was released at the lowest treatment temperature of $250^{\circ} \mathrm{C}$, a better removal was achieved at higher treatment temperatures. At the highest treatment temperature tested, $450^{\circ} \mathrm{C}$, a removal efficiency of $98 \%$ was achieved, resulting in a residual content of $27 \mathrm{mg} \mathrm{Hg} / \mathrm{kg}$.

The leachable concentrations of mercury according to the TCLP test of the treated sludge are shown in Fig. 2 as a function of time and treatment temperature. After treatment at $250^{\circ} \mathrm{C}$ the mercury concentrations remained above the allowable TCLP limit of $0.2 \mathrm{mg} / \mathrm{l}$ for the entire range of residence times. As such, the treated waste still is classified as a hazardous waste according to the USEPA criteria [29], although after the longest treatment time tested, the concentration in the leachate, $2.5 \mathrm{mg} / \mathrm{l}$, was already substantially reduced over that of the untreated mercurial sludge $(10.1 \mathrm{mg} / \mathrm{l})$. When treated at $350^{\circ} \mathrm{C}$ for $25 \mathrm{~min}$ or more, the leachability of mercury of the residue 
Table 6

Thermodynamic parameters $(\Delta G, \Delta H, K e)$ of the kinetic reaction mechanism.

\begin{tabular}{llll}
\hline Reactions & $\Delta G_{450^{\circ} \mathrm{C}}\left(\mathrm{kJ} \mathrm{mol}^{-1}\right)$ & $\Delta H_{4500^{\circ} \mathrm{C}}\left(\mathrm{kJ} \mathrm{mol}^{-1}\right)$ & $\mathrm{Ke}_{4500^{\circ} \mathrm{C}}$ \\
\hline$\left(\mathrm{R}_{1}\right)$ & $-3.06 \times 10^{2}$ & $-3.65 \times 10^{2}$ & 147.83 \\
$\left(\mathrm{R}_{2}\right)$ & 4.81 & $1.57 \times 10^{2}$ & $9.23 \times 10^{-1}$ \\
$\left(\mathrm{R}_{3}\right)$ & $-5.36 \times 10^{1}$ & 41.42 & 2.44 \\
$\left(\mathrm{R}_{4}\right)$ & $-4.13 \times 10^{4}$ & $-1.76 \times 10^{5}$ & $2.32 \times 10^{298}$ \\
$\left(\mathrm{R}_{5}\right)$ & -3.38 & $2.35 \times 10^{2}$ & 1.06 \\
$\left(\mathrm{R}_{6}\right)$ & $-2.2 \times 10^{2}$ & $3.2 \times 10^{2}$ & 38.12 \\
\hline
\end{tabular}

complied to the TCLP limit. Treatment at $450^{\circ} \mathrm{C}$ resulted in a strong reduction of TCLP leachable concentrations, regardless of exposure time.

\subsection{Thermodynamic analysis of the reaction scheme}

A scheme of six reactions (Table 2) was proposed to describe the thermal decomposition of the mercurial sludge. The reactions were selected based on the properties of the mercurial sludge and the fractionation of mercury. According to the procedure outlined above, the Gibbs free energy for each reaction was calculated, and parameters of the kinetic models were determined to fit the experimental data.

The proposed scheme of reactions involves the two types of thermal decomposition mechanisms reported in literature [37]. One type involves congruent dissociative vaporization of a solid or liquid reactant $R(\mathrm{~s} / \mathrm{l})$ into gaseous products $\mathrm{A}(\mathrm{g})$ and $\mathrm{B}(\mathrm{g})$. The other type involves incongruent dissociative vaporization with formation of a solid product $\mathrm{A}(\mathrm{s})$ and a gaseous product $\mathrm{B}(\mathrm{g})$. These reactions thus may describe the chemistry of the thermal decomposition in the solid particle and subsequent reactions of the released mercury in the gas phase. The particle size, diffusional resistances and temperature are the factors that determine the reaction limiting steps and hence define the dominant reactions and mechanisms.

The probability of occurrence of each reaction was evaluated from the Gibbs free energy $(\Delta G)$. The thermodynamic properties $\Delta G_{j}, \Delta H_{j}$ and $K e_{j}$ for each reaction considered were assessed for the highest working temperature of the furnace $\left(450^{\circ} \mathrm{C}\right)$ (Table 6$)$.

From a thermodynamic viewpoint, chemical reactions will proceed spontaneously if the Gibbs free energy $\Delta G$ is negative. Only $R_{2}$ exhibited a positive $\Delta G$. O'Neil et al. [41] already reported that, for similar operating conditions, the formation of metallic $\mathrm{Hg}$ from $\mathrm{HgO}$ in the gas phase is not expected. The high value obtained for the equilibrium constant of reaction $R_{4}$ is in agreement with previous results reported by Navarro et al. [50]. Enthalpy values $(\Delta H)$ reveal that reactions $R_{1}$ and $R_{4}$ are exothermic while the other reactions are endothermic.

This reaction pattern, which includes five heterogeneous (gas-solid phase and liquid-gas phase) reactions and one homogeneous (gas phase) reaction, was used in the reaction order model to obtain the kinetic parameters (see Section 2.5.2). It has been assumed that $R_{1}, R_{3}$ and $R_{5}$ occur in parallel.

\subsection{Kinetics of the reactions occurring during thermal treatment}

\subsubsection{Friedman method}

Values of the apparent activation energy obtained using the Friedman method ranged between 195 and $265 \mathrm{~kJ} \mathrm{~mol}^{-1}$. This wide range could be due to differences in dominant reaction mechanism as a function of temperature and reaction time, which is common in heterogeneous phase and multi-step processes. Furthermore, the Friedman's method is susceptible to experimental noise. Global activation energy is being calculated, and the obtained values of $E$ are therefore not representative for any individual reaction step. Nevertheless, a very good fit to the experimental data was obtained

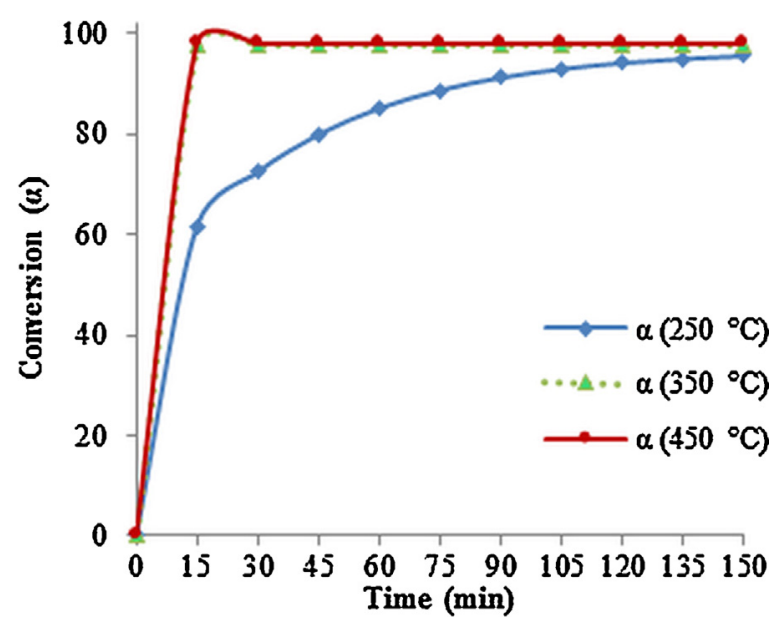

Fig. 3. Conversion profiles of the kinetic model at the three retorting temperatures (Note that conversion $(\alpha)$ values are expressed in \%).

$\left(R^{2}=0.938\right)$, and the results served as a useful global estimation for subsequent analyses as discussed below.

\subsubsection{Reaction order model}

Chemical reactions $\left(R_{1}\right)$ and $\left(R_{3}\right)-\left(R_{6}\right)$ were considered in deriving the kinetic model for thermal decomposition of the mercurial sludge. The phase change reactions were disaggregated before analysis to simplify the mathematical procedure. Thus, reactions $\left(R_{1}\right)$ and $\left(R_{3}\right)-\left(R_{6}\right)$ (Table 2 ) were supplemented with:

$$
\begin{aligned}
& \mathrm{HgCl}_{2(\mathrm{aq})} \rightarrow \mathrm{HgCl}_{2(\mathrm{~g})} \\
& \mathrm{H}_{2} \mathrm{O}_{(\mathrm{aq})} \rightarrow \mathrm{H}_{2} \mathrm{O}_{(\mathrm{g})} \\
& \mathrm{Hg}_{(\mathrm{c})} \rightarrow \mathrm{Hg}_{(\mathrm{g})} \\
& \mathrm{HgS}_{(\mathrm{c})} \rightarrow \mathrm{HgS}_{(\mathrm{g})} \\
& \mathrm{HgSO}_{4(\mathrm{c})} \rightarrow \mathrm{HgSO}_{4(\mathrm{~g})}
\end{aligned}
$$

In this study, the kinetic models representing deceleratory $\alpha-T$ curves (Table 3 ) were considered based on the experimental conversion curves, where no initial deceleration was observed (Fig. 3).

Different processes may govern the mercury conversion at low $\left(250^{\circ} \mathrm{C}\right)$ versus at high $\left(450^{\circ} \mathrm{C}\right)$ temperature. First, the nine kinetic equations which correspond to the nine mechanisms mentioned above were solved together with the mass balance, and the conversions $(\alpha)$ obtained this way were compared with the experimentally observed conversions for each temperature following the workflow depicted in Fig. 1. The results are presented in Fig. 4a and b.

Subsequently, predicted conversions $(\alpha)$ as a function of time were, for the nine mechanistic models, compared with the experimentally observed conversions. The lack of a good fit between $\alpha$-values calculated using any of the considered kinetic models, and the experimentally determined $\alpha$ for low residence times ( $<15 \mathrm{~min}$ ) may suggest that a combination of mechanisms may be ruling the process. At residence times above $15 \mathrm{~min}$, good fits were found, that, however, differed between the two temperatures considered. At a retorting temperature of $250{ }^{\circ} \mathrm{C}$ the $D_{1}$-diffusion mechanism was considered the controlling step of the process whereas at $450{ }^{\circ} \mathrm{C}$ a combination of the diffusion mechanism $\left(D_{1}\right)$ and the third order reaction mechanism $\left(F_{3}\right)$ appeared to control the process. This is suggested by a good fit of the respective models to the experimental data over the whole range of conversions (Fig. 4). 

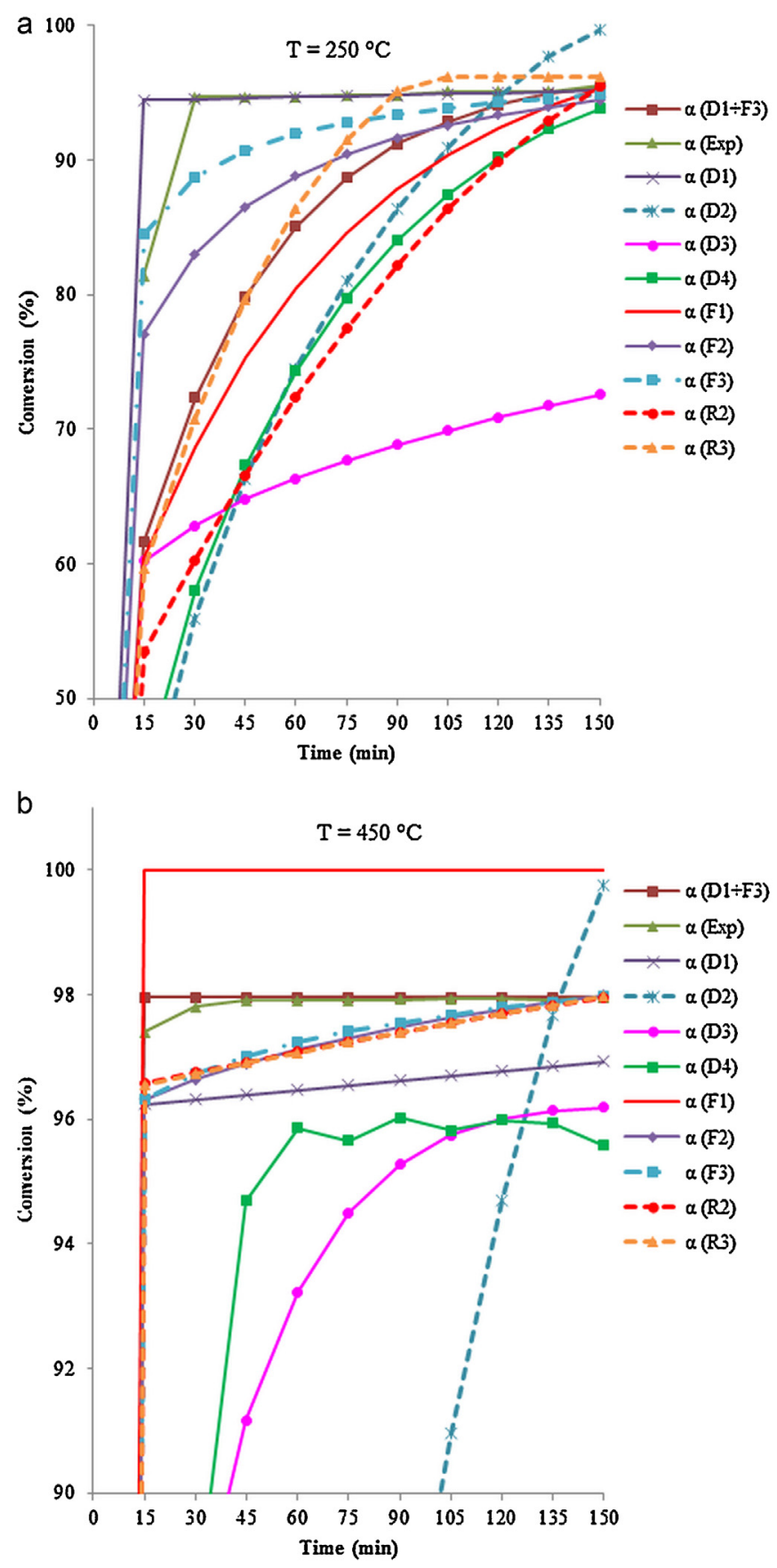

Fig. 4. (a) Comparison of thermal decomposition mechanisms at lowest temperature tested $\left(250^{\circ} \mathrm{C}\right)$. (Note that curves represent the model conversion curve $(\alpha$ $\left.\left(D_{1}+F_{3}\right)\right)$, the experimental conversion curve $(\alpha(\exp ))$ and the conversion curves from the nine kinetic models $\left(\alpha\left(D_{1}, D_{2}, D_{3}, D_{4}, F_{1}, F_{2}, F_{3}, R_{2}\right.\right.$ and $\left.\left.R_{3}\right)\right)$ reported in Table 3.) (b) Comparison of thermal decomposition mechanisms at highest temperature tested $\left(450^{\circ} \mathrm{C}\right)$. (Note that curves represent the model conversion curve $(\alpha$ $\left.\left(D_{1}+F_{3}\right)\right)$, the experimental conversion curve $(\alpha(\exp ))$ and the conversion curves from the nine kinetic models $\left(\alpha\left(D_{1}, D_{2}, D_{3}, D_{4}, F_{1}, F_{2}, F_{3}, R_{2}\right.\right.$ and $\left.\left.R_{3}\right)\right)$ reported in Table 3.)

The kinetic parameters $\alpha, k$ and $n$ are presented in Table 7 . These kinetic parameters result from a global empiric kinetic model used as a first approximation to describe the thermal decomposition of this multi-component and poly-disperse system (mercurial sludge). More thermal decomposition studies of these mercury wastes should be done to investigate the kinetics for each of the proposed reactions by experimental simulation. Nevertheless, the apparent activation energies obtained for each reaction are in
Table 7

Kinetic parameters $\left(\alpha_{f}, k_{j}, n_{r}\right)$ from adjusted kinetic model for each operating temperature.

\begin{tabular}{|c|c|c|c|}
\hline Kinetic parameters & $250^{\circ} \mathrm{C}$ & $350^{\circ} \mathrm{C}$ & $450^{\circ} \mathrm{C}$ \\
\hline$k_{1}\left(\min ^{-1}\right)$ & $1.56 \times 10^{-22}$ & $2.51 \times 10^{-19}$ & $5.24 \times 10^{-17}$ \\
\hline $\mathrm{Ea}_{1}\left(\mathrm{~kJ} \mathrm{~mol}^{-1}\right)$ & 199.99 & - & - \\
\hline$A_{1}\left(\min ^{-1}\right)$ & 0.015 & - & - \\
\hline$k_{3}\left(\min ^{-1}\right)$ & 3.59 & 4.41 & 10.79 \\
\hline $\mathrm{Ea}_{3}\left(\mathrm{~kJ} \mathrm{~mol}^{-1}\right)$ & 208.76 & - & - \\
\hline$A_{3}\left(\min ^{-1}\right)$ & $1.4 \times 10^{18}$ & - & - \\
\hline$k_{4}\left(\min ^{-1}\right)$ & $1.1 \times 10^{-38}$ & $5.84 \times 10^{-30}$ & $5.47 \times 10^{-24}$ \\
\hline $\mathrm{Ea}_{4}\left(\mathrm{~kJ} \mathrm{~mol}^{-1}\right)$ & 515.44 & - & - \\
\hline$A_{4}\left(\min ^{-1}\right)$ & $9.53 \times 10^{13}$ & - & - \\
\hline$k_{5}\left(\min ^{-1}\right)$ & 0.59 & 1.54 & 10.79 \\
\hline $\mathrm{Ea}_{5}\left(\mathrm{~kJ} \mathrm{~mol}^{-1}\right)$ & 94.22 & - & - \\
\hline$A_{5}\left(\min ^{-1}\right)$ & $8.36 \times 10^{7}$ & - & - \\
\hline$k_{6}\left(\min ^{-1}\right)$ & $1.03 \times 10^{-37}$ & $2.08 \times 10^{-29}$ & $1.69 \times 10^{-23}$ \\
\hline $\mathrm{Ea}_{6}\left(\mathrm{~kJ} \mathrm{~mol}^{-1}\right)$ & 508.81 & - & - \\
\hline$A_{6}\left(\min ^{-1}\right)$ & $9.59 \times 10^{13}$ & - & - \\
\hline$k_{7}\left(\min ^{-1}\right)$ & $5.15 \times 10^{-10}$ & $1.18 \times 10^{-8}$ & $1.62 \times 10^{-8}$ \\
\hline $\mathrm{Ea}_{7}\left(\mathrm{~kJ} \mathrm{~mol}^{-1}\right)$ & 523.39 & - & - \\
\hline$A_{7}\left(\min ^{-1}\right)$ & $9.59 \times 10^{13}$ & - & - \\
\hline$k_{8}\left(\min ^{-1}\right)$ & $1 \times 10^{-20}$ & $1 \times 10^{-14}$ & $1 \times 10^{-10}$ \\
\hline $\mathrm{Ea}_{8}\left(\mathrm{~kJ} \mathrm{~mol}^{-1}\right)$ & 333.40 & - & - \\
\hline$A_{8}\left(\min ^{-1}\right)$ & $1 \times 10^{14}$ & - & - \\
\hline$k_{9}\left(\min ^{-1}\right)$ & $2.83 \times 10^{-2}$ & $5.38 \times 10^{-1}$ & $5.73 \times 10^{-1}$ \\
\hline $\mathrm{Ea}_{9}\left(\mathrm{~kJ} \mathrm{~mol}^{-1}\right)$ & 197.09 & - & - \\
\hline$A_{9}\left(\min ^{-1}\right)$ & $1 \times 10^{14}$ & - & - \\
\hline$k_{10}\left(\min ^{-1}\right)$ & $4.14 \times 10^{-2}$ & $7.98 \times 10^{-2}$ & $1.15 \times 10^{-1}$ \\
\hline $\mathrm{Ea}_{10}\left(\mathrm{~kJ} \mathrm{~mol}^{-1}\right)$ & 206.75 & - & - \\
\hline$A_{10}\left(\min ^{-1}\right)$ & $1 \times 10^{14}$ & - & - \\
\hline$k_{11}\left(\min ^{-1}\right)$ & $4 \times 10^{-20}$ & $1 \times 10^{-14}$ & $1.93 \times 10^{-2}$ \\
\hline $\mathrm{Ea}_{11}\left(\mathrm{~kJ} \mathrm{~mol}^{-1}\right)$ & 524.8 & - & - \\
\hline$A_{11}\left(\min ^{-1}\right)$ & $9.99 \times 10^{29}$ & - & - \\
\hline$\alpha_{f}(\%)$ & $9.75 \times 10^{1}$ & $9.76 \times 10^{1}$ & $9.79 \times 10^{1}$ \\
\hline$n_{r}$ & $7.86 \times 10^{-1}$ & 1.03 & 1 \\
\hline
\end{tabular}

a Values of activation energy $(E)$ and pre-exponential factor $(A)$ obtained for the entire range of temperature.

agreement with values reported in the literature where a range of values between $74 \mathrm{~kJ} \mathrm{~mol}^{-1}$ for $\mathrm{CuSO}_{4}$ and $518 \mathrm{~kJ} \mathrm{~mol}^{-1}$ for $\mathrm{CaO}$ are reported [37].

The results suggest that the reaction mechanisms governing the thermal decomposition change with time. At the beginning, the external diffusion of the gas $\left(\mathrm{O}_{2}\right)$ through the sludge particle is the controlling mechanism as the compound $\left(\mathrm{O}_{2}\right)$ diffuses in the superficial phase and in outer layers of the sludge particle. With time, the thickness of the ashes layer will increase due to thermal decomposition of the solid-phase reactants (e.g. $\mathrm{HgS}$ and $\mathrm{HgSO}_{4}$ ) and the diffusion of gaseous products $\left(\mathrm{Hg}, \mathrm{O}_{2}, \mathrm{SO}_{2}\right.$ and $\left.\mathrm{Cl}_{2}\right)$ through the ashes will increasingly control the kinetics of the reactions. However, it should be reminded that the nine kinetic models used for comparison were established for mono-components and monodisperse systems. In this case study, the solid matrix is much more complex (poly-disperse and multi-component) and thus the kinetic parameters may have been more affected by diffusional processes.

It has been reported by Kafarov [51] that the equation of Prout-Tompkins is well suited for polydisperse systems and/or where a component is separated in different phases. It is very effective when there are changes in the diffusive stage that controls the process.

\subsubsection{Application of the model}

The furnace model and the kinetic expressions were used to estimate the effect of the reaction temperature on the treatment efficiency. Fig. 5a-c depicts the evolution of various mercury compounds in the sludge with time for different treatment temperatures, as estimated based on the kinetic model. Results show a fast reduction of the mercury compounds $\left(\mathrm{Hg}, \mathrm{HgCl}_{2}, \mathrm{HgSO}_{4}\right.$ and $\left.\mathrm{HgS}\right)$ mass in the solid matrix (mercurial sludge) with the temperature. 

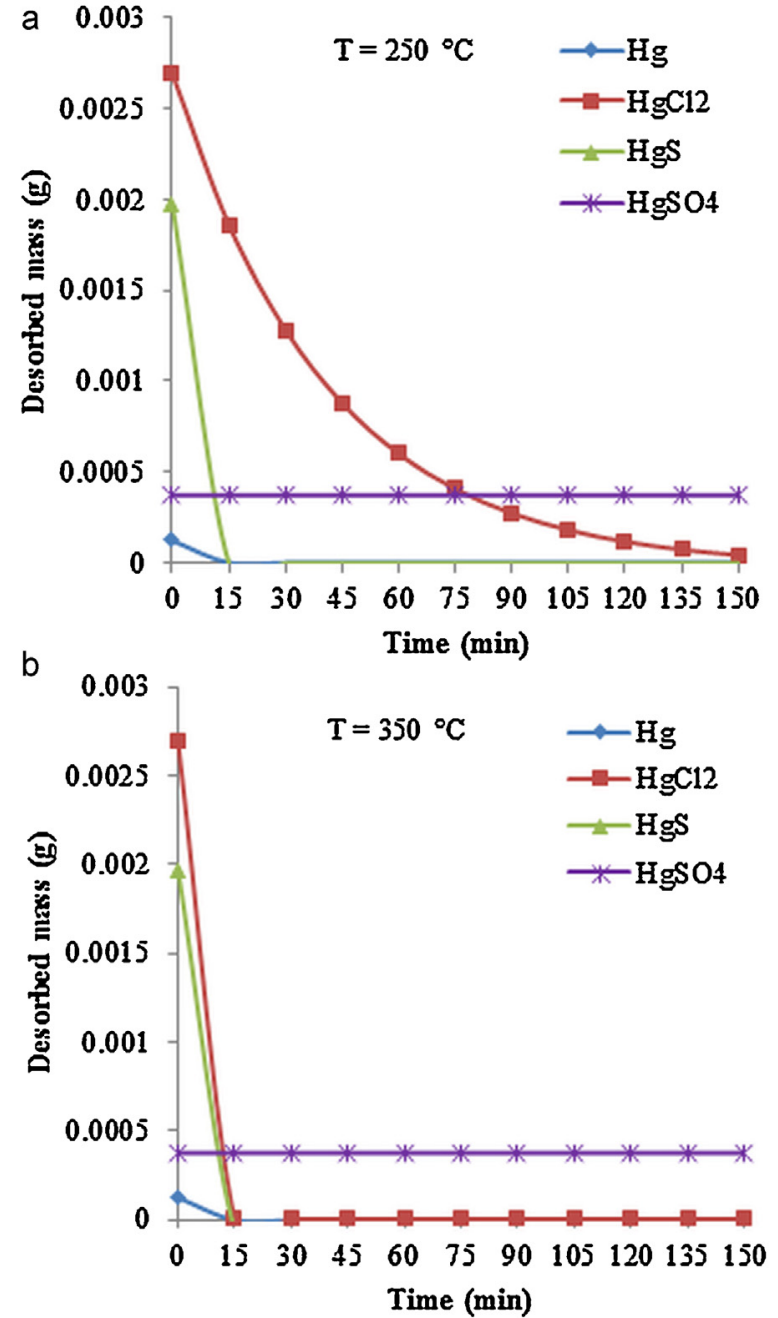

C

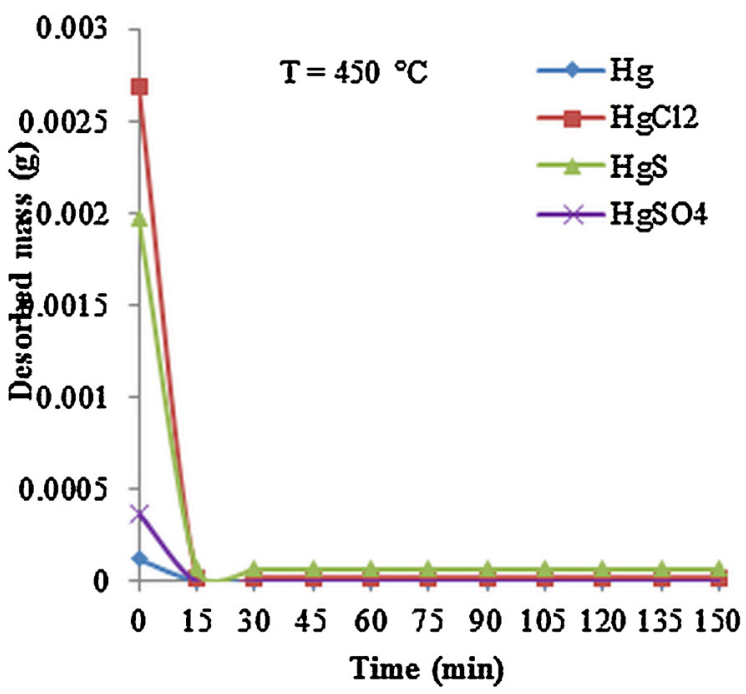

Fig. 5. (a) Effect of the residence time on mercury removal at $250{ }^{\circ} \mathrm{C}$. (Note that $\mathrm{Hg}$, $\mathrm{HgCl}_{2}, \mathrm{HgS}, \mathrm{HgSO}_{4}$ represent the desorbed mass of each mercury compound referred to $3 \mathrm{~g}$ of sludge.) (b) Effect of the residence time on mercury removal at $350^{\circ} \mathrm{C}$. (Note that $\mathrm{Hg}, \mathrm{HgCl}_{2}, \mathrm{HgS}, \mathrm{HgSO}_{4}$ represent the desorbed mass of each mercury compound referred to $3 \mathrm{~g}$ of sludge.) (c) Effect of the residence time on mercury removal at $450^{\circ} \mathrm{C}$. (Note that $\mathrm{Hg}, \mathrm{HgCl}_{2}, \mathrm{HgS}, \mathrm{HgSO}_{4}$ represent the desorbed mass of each mercury compound referred to $3 \mathrm{~g}$ of sludge.)
Table 8

Comparison between maximum conversion values achieved by the experimental data and the simulated model. (Note that $\alpha$ values are expressed in \%.).

\begin{tabular}{|c|c|c|c|c|c|c|}
\hline \multirow[t]{2}{*}{ Time (min) } & \multicolumn{2}{|l|}{$\alpha_{250^{\circ} \mathrm{C}}$} & \multicolumn{2}{|l|}{$\alpha_{350^{\circ} \mathrm{C}}$} & \multicolumn{2}{|l|}{$\alpha_{450^{\circ} \mathrm{C}}$} \\
\hline & Experiment & Model & Experiment & Model & Experiment & Model \\
\hline 5 & 43 & 51.76 & 95.3 & 95.4 & 97 & 97.05 \\
\hline 10 & 62.7 & 57.02 & 95.6 & 97.45 & 97.08 & 97.94 \\
\hline 15 & 81.4 & 61.6 & 96.5 & 97.56 & 97.4 & 97.95 \\
\hline 30 & 94.7 & 72.4 & 97.1 & 97.57 & 97.8 & 97.96 \\
\hline 60 & 94.7 & 85.1 & 97.2 & 97.57 & 97.91 & 97.96 \\
\hline 90 & 94.8 & 91.2 & 97.3 & 97.57 & 97.92 & 97.96 \\
\hline 120 & 95.1 & 94.1 & 97.3 & 97.57 & 97.93 & 97.96 \\
\hline 150 & 95.5 & 95.48 & 97.56 & 97.57 & 97.96 & 97.96 \\
\hline
\end{tabular}

This trend agrees with the chemical reaction mechanism proposed which includes the phase change reactions and diffusional resistances. At $250^{\circ} \mathrm{C}$, mercury chloride was converted at a much slower rate than the other mercury forms. At 350 and $450{ }^{\circ} \mathrm{C}$, all mercury compounds were released from the matrix within $15 \mathrm{~min}$. At retorting temperatures of $250^{\circ} \mathrm{C}$ (Fig. 5a) and $350^{\circ} \mathrm{C}$ (Fig. 5b), no $\mathrm{HgSO}_{4}$ desorption was predicted to occur. This is expected because $\mathrm{HgSO}_{4}$ has a temperature of thermal decomposition of $500^{\circ} \mathrm{C}$ [38].

The profiles of desorbed mass obtained at each working temperature are consistent with the experimental observations reported by Busto et al. [10], where the effect of the retorting temperature was much stronger than the effect of exposure time. Nevertheless, the main explanation for the occurrence of this phenomenon could be associated with the controlling reaction mechanism that takes place at low $\left(250^{\circ} \mathrm{C}\right)$ and high temperature $\left(350-450^{\circ} \mathrm{C}\right)$.

Experimentally observed maximum conversions were compared with model calculated data (Table 8).

At retorting temperature of $250^{\circ} \mathrm{C}$, the kinetic model obtained by simulation did not result in a suitable adjustment with the experimental values. Contrarily, a very good fit of the experimental conversion with the modelled conversion values was achieved for $350^{\circ} \mathrm{C}$ and $450^{\circ} \mathrm{C}$. This could be linked with a change in the controlling reaction mechanism during the thermal process. Nevertheless, the statistical significance of the conversion values at 250 and $450^{\circ} \mathrm{C}$ was verified. The P values obtained at $250^{\circ} \mathrm{C}$ from the Rank sum and Kruskal-Wallis statistical tests were 0.119 and 0.175 $(P>0.05)$, respectively. Equally, $P$ values obtained at $450{ }^{\circ} \mathrm{C}$ from the Rank sum and Kruskal-Wallis statistical tests were 0.167 and 0.097 , respectively, demonstrating that non-significant differences exist between experimental data and the proposal model.

The added value of the knowledge of the mercury reaction mechanism during thermal treatment of solid wastes is a step into the process design at higher scales such as pilot or full-scale plant. It allows to elucidate the most significant parameters to be taken into account and to predict the effects of different reaction conditions.

\section{Conclusions}

In the present research a kinetic reaction mechanism that describes mercury removal during thermal treatment of a solid waste has been proposed. A set of six reactions involving mercury conversions and including homogeneous and heterogeneous phase interactions, was considered. The proposed reactions pattern was thermodynamically evaluated and kinetic parameters were obtained. Model predictions were in good agreement with the experimental data. The effect of reaction temperature was much stronger than the effect of residence time. Two steps controlling the kinetics of the thermal decomposition were identified. The $D_{1}$ diffusion mechanism appeared to govern the process at $250{ }^{\circ} \mathrm{C}$ and high residence times, whereas at $450^{\circ} \mathrm{C}$ a combination of the diffusion mechanism $\left(D_{1}\right)$ and the third order reaction mechanism $\left(F_{3}\right)$ fitted the kinetics of the conversions. Contrarily, at low residence 
times ( $<15 \mathrm{~min}$ ) for both compared temperatures, a combination of mechanisms may be ruling the process. The developed models can be applied in engineering calculations to dimension the installations and determine the optimal conditions to treat a mercury containing sludge.

\section{Acknowledgements}

This study was financially supported by the Belgian Programme for Institutional University Co-operation (VLIR-UCLV). Project \# 7: "Environmental Education and Cleaner Technologies". Especially we want to acknowledge professors of Ghent University that are included in author's relation for their contributions in the development of this research and the technicians of the Laboratory for Analytical Chemistry and Applied Ecochemistry, Bioengineering Science Faculty of Ghent University for their support in the experimental work.

\section{References}

[1] X.Y. Zhang, O. ChaoWang, S. Oing Zhang, X.J. Sun, Z.S. Zhang, Stabilization/solidification $(S / S)$ of mercury-contaminated hazardous wastes using thiol-functionalized zeolite and Portland cement, J. Hazard. Mater. 168 (2009) 1575-1580.

[2] A.T. Reis, S.R. Morais, C. Araújo, J.P. Coelho, Mercury contamination in the vicinity of a chlor-alkali plant and potential risks to local population, Sci. Total Environ. 407 (2009) 2689-2700.

[3] K. Telmer, M. Veiga, World emissions of mercury from artisanal and small scale gold mining, in: N. Pirrone, R. Mason (Eds.), Interim Report of the UNEP Global Partnership on Atmospheric Mercury Transport and Fate Research, 2008, Available from: http://www.chem.unep.ch/mercury (retrieved 10.10.12) (Chapter 6).

[4] E.B. Swain, P.M. Jakus, G. Rice, F. Lupi, P.A. Maxon, J.M. Pacyna, A. Penn, S.J. Spiegel, M.M. Veiga, Socioeconomic consequences of mercury use and pollution, Ambio 36 (2007) 46-62.

[5] A.B. Mukherjee, R. Zevenhoven, J. Brodersen, L.D. Hylander, P. Bhattacharya, Mercury in waste in the European Union: sources, disposal methods and risks, Resour. Conserv. Recycl. 42 (2004) 155-182.

[6] E.G. Pacyna, J.M. Pacyna, F. Steenhuisen, S. Wilson, Global anthropogenic mercury emission inventory for 2000, Atmos. Environ. 40 (2006) 4048-4063.

[7] United Nations Environment Programme (UNEP), Regional Awarenessraising Workshop on Mercury Pollution, 2007, Available from: http://www.chem.unep.ch/Mercury/Pretoria-proceedings-finalPDFwriter.pdf (retrieved 10.10.12).

[8] USEPA, Land Disposal Restrictions Regulations for Mercury-containing Non-wastewaters. R 40 CFR Part 273, 2008, Available from: http://www.epa.gov/epawaste/hazard/tsd/mercury/treatmnt.htm (retrieved 6.11.10, last updated 19.07.08, revision date, 10.06.10)

[9] USEPA, Office of Research and Development, Capsule Report, Aqueous Mercury Treatment, EPA-625-R-97-004, 1997, Available from: ht**tp://www.epa.gov/ORD/NRMRL/pubs/625r97004/625r97004.pdf (retrieved 10.10.12)

[10] Y. Busto, X. Cabrera, F.M.G. Tack, M.G. Verloo, Potential of thermal treatment for decontamination of mercury containing wastes from chlor-alkali industry, J. Hazard. Mater. 186 (2011) 114-118.

[11] P.R. De Percin, Application of thermal desorption technologies to hazardous waste sites, J. Hazard. Mater. 40 (1995) 203-209.

[12] M.T. Smith, F. Berruti, A.K. Mehrotra, Thermal desorption treatment of contaminated soils in a novel batch thermal reactor, Ind. Eng. Chem. Res. 40 (2001) 5421-5430.

[13] T.C. Chang, J.H. Yen, On-site mercury-contaminated soils remediation by using thermal desorption technology, J. Hazard. Mater. B128 (2006) 208-217.

[14] F. Taube, L. Pommer, T. Larsson, A. Shchukarev, A. Nordin, Soil remediation-mercury speciation in soil and vapor phase during thermal treatment, Water Air Soil Pollut. 193 (2008) 155-163.

[15] K.C. Galbreath, C.J. Zygarlicke, Mercury transformations in coal combustion flue gas, Fuel Process. Technol. 65 (2000) 289-310.

[16] H. Agarwal, H.G. Stenger, Development of a predictive kinetic model for homogeneous Hg oxidation data, Math. Comput. Model. 45 (2007) 109-125.

[17] M.Xu, Y. Qiao, J. Liu, C. Zheng, Kinetic calculation and modelling of trace element reactions during combustion, Powder Technol. 180 (2008) 157-163.

[18] N.R. Sliger, J.C. Kramlich, N.M. Marinov, Towards the development of a chemical kinetic model for the homogeneous oxidation of mercury by chlorine species, Fuel Process. Technol. 65-66 (2000) 423-438.

[19] C.L. Senior, A.F. Sarofim, T. Zeng, J.J. Helble, R. Mamani-Paco, Gas phase transformations of mercury in coal-fired power plants, Fuel Process. Technol. 63 (2000) $197-213$.

[20] J.R. Edwards, R.K. Srivastava, J.D. Kilgroe, A study of gas-phase mercury speciation using detailed chemical kinetics, J. Air Waste Manage. Assoc. 51 (2001) 869-877.
[21] S. Niksa, J.J. Helble, N. Fujiwara, Kinetic modelling of homogeneous mercury oxidation: the importance of $\mathrm{NO}$ and $\mathrm{H}_{2} \mathrm{O}$ in predicting oxidation in coalderived systems, Environ. Sci. Technol. 35 (2001) 3701-3706.

[22] M. Xu, Y. Qiao, C. Zheng, L. Li, J. Liu, Modelling of homogeneous mercury speciation using detailed chemical kinetics, Combust. Flame 132 (2003) 208-218.

[23] L. Li, P. Deng, A. Tian, M. Xu, C. Zheng, N. Wong, A study on the reaction mechanism and kinetic oxidation of mercury by chlorine species, J. Mol. Struct. 625 (2003) 277-281.

[24] C. Zheng, J. Liu, Z. Liu, M. Xu, Y. Liu, Kinetic mechanism studies on reactions of mercury and oxidizing species in coal combustion, Fuel 84 (2005) 1215-1220.

[25] B. Krishnakumar, J.J. Helble, Understanding mercury transformations in coalfired power plants: evaluation of homogeneous $\mathrm{Hg}$ oxidation mechanisms, Environ. Sci. Technol. 41 (2007) 7870-7875

[26] B. Krishnakumar, J.J. Helble, Determination of transition state theory rate constants to describe mercury oxidation in combustion systems mediated by $\mathrm{Cl}, \mathrm{Cl}_{2}, \mathrm{HCl}$ and $\mathrm{HOCl}$, Fuel Process. Technol. 94 (2012) 1-9.

[27] B.V. L'vov, Kinetics and mechanism of thermal decomposition of mercuric oxide, Thermochim. Acta 333 (1999) 21-26.

[28] B.V. L'vov, V.L. Ugolkov, F.F. Grekov, Kinetics and mechanism of free-surface vaporization of zinc, cadmium and mercury oxides analyzed by the third-law method, Thermochim. Acta 411 (2004) 187-193.

[29] USEPA, Toxicity Characterization Leaching Procedure (TCLP), Final Rule 261, 55 FR, Government Printing Office, Washington, DC, 1990, pp. 11798-11877, Available from: http://www.epa.gov/epawaste/hazard/ tsd/mercury/treatmnt.htm (retrieved 6.11.10, last updated, 19.07.08, revision date, 10.06.10).

[30] J. Buffle, K.J. Wikinson, M.L. Tercier, N. Parthasarathy, in: F. Palmisano, L. Sabbatini, P.G. Zambonin (Eds.), Reviews on Analytical Chemistry, Euroanalysis IX, Societa Chimica Italiana, 1997, pp. 67-82.

[31] C.M. Neculita, G.J. Zagury, L. Deschenes, Mercury speciation in highly contaminated soils from chlor-alkali plants using chemical extractions, J. Environ. Qual. 34 (2005) 255-262.

[32] C. Washburn, E. Hill, Mercury retorts for the processing of precious metals and hazardous wastes, JOM 55 (2003) 45-50.

[33] USEPA, Treatment Technologies for Mercury in Soil, Waste, and Water. Part II. Mercury Treatment Technology Summaries. Part II-A: Treatment Technologies Applicable to Soil and Waste, August, 2007, Available from: http://www.epa.gov/tio/download/remed/542r07003.pdf

[34] M.I. Morris, R.J. Sams, G. Gillis, R.W. Helsel, E.S. Alperin, T.J. Geisler, A. Groen, D. Root, Bench and Pilot Scale Demonstration of Thermal Desorption for Removal of Mercury from the Lower East Fork Poplar Creek Floodplain Soils. Technical Report 950216-129, 1995, Available in: http://www.ntis.gov/search/product.aspx?ABBR=DE95009693

[35] J. Blanchard, R. Stamnes, Engineering Forum Issue Paper: Thermal Desorption Implementation Issues. EPA 540/F-95/031, 1997, Available in: http://www.epa.gov/swertio1/tsp/download/tdissue.pdf

[36] B.V.L'vov, The physical approach to the interpretation of the kinetics and mechanisms of thermal decomposition of solids: the state of the art, Thermochim. Acta 373 (2001) 97-124.

[37] B.V. L'vov, Thermal decomposition of solids and melts, in: Kinetics and Methodology. New Thermochemical Approach to the Mechanism, Kinetics and Methodology, Springer, Russia, 2007, ISBN 978-1-4020-5671-0.

[38] J.M. Smith, Chemical Engineering Kinetics, 6th ed., McGraw-Hill, Inc., Mexico, 1991, ISBN 0-07-058710-8.

[39] J.M. Smith, H.C. Van Ness, Introduction to Chemical Engineering Thermodynamics, 3rd ed., McGraw-Hill, USA, 1975.

[40] P. Patnaik, Handbook of Inorganic Chemicals, Monographs 559 (mercury) through 580 (mercury [II] sulfide), McGraw-Hill, New York, 2003, Available from: http://library.ukrweb.net/book/chemistry/inorganic/patnaik\%20p.\%20 \%20handbook\%20of\%20inorganic\%20chemicals/94398_toc.pdf (retrieved 10.10.12).

[41] M.J. O'Neil, A. Smith, P.E. Heckelman, The Merck Index, 13th ed., Merck and Co., Inc., Whitehouse Station, USA, 2001.

[42] Y. Busto, F.M.G. Tack, X. Cabrera, Mercury mobility and availability in highly contaminated solid wastes from a chlor-alkali plant, Int. J. Environ. Sust. Dev. 11 (2012) 3-18.

[43] D.W. Green, R.H. Perry, Perry's Chemical Engineers' Handbook, 8th ed., McGraw-Hill, USA, 2007.

[44] J.A. Dean, Lange's Handbook of Chemistry, 15th ed., McGraw-Hill, New York, USA, 1968.

[45] R. Hooke, T.A. Jeeves, 'Direct search' solution of numerical and statistical problems, J. Assn. Comp. Mach. 8 (1961) 212-219.

[46] T.M. Alkhamis, M.A. Ahmed, A modified Hooke and Jeeves algorithm with likelihood ratio performance extrapolation for simulation optimization, Eur. J. Oper. Res. 174 (2006) 1802-1815.

[47] R.V. Dukkipati, Numerical Methods, New Age International, USA, 2010, ISBN (13): 978-81-224-2978-7.

[48] M. Hollander, D.A. Wolfe, Nonparametric statistical methods, John Wiley \& Sons, Inc., Hoboken, NJ, USA, 1999.

[49] J.L. Devore, K.N. Berk, Modern Mathematical Statistics with Applications, 2nd ed. Springer, New York, USA, 2012.

[50] A. Navarro, I. Cañadas, D. Martinez, J. Rodriguez, J.L. Mendoza, Application of solar thermal desorption to remediation of mercury-contaminated soils, Sol. Energy 83 (2009) 1405-1414.

[51] V. Kafarov, Cybernetic Methods in Chemistry and Chemical Engineering, MIR, Moscow, 1977 